\title{
Technique
}

\section{Protective finger device for use in endoscopic procedures}

MELVIN L. BUTLER From the Gastroenterology Service, Tripler Army Medical Center, Honolulu, Hawaii

The use of fiberoptic endoscopes for the diagnosis of gastrointestinal disorders has increased markedly in the last few years. These instruments are of particular value in cases of upper gastrointestinal haemorrhage; indeed it is the practice in many centres to perform 'emergency' endoscopy on such patients in an attempt to locate the bleeding site. Frequently the tenuous physiological state of the bleeding patient prohibits sedation and the result is a frightened, somewhat uncooperative individual in spite of counselling and reassurance by the physician. In addition many patients with upper gastrointestinal bleeding will have associated acute alcoholism which will further complicate the endoscopic procedure.

During such situations, most seasoned endoscopists have had the disquieting experience of having such a patient bite his fingers at the time the instrument is being introduced into the oesophagus. I have developed a simple device to ensure that such accidental injuries do not occur.

\section{Design}

A thin sheet of 0.003 hardness aluminium is moulded to fit the endoscopist's index finger, or, if preferred, both the index and second fingers of the left hand. The device is easily assembled in the orthopaedic section of a hospital or in any small machine shop.

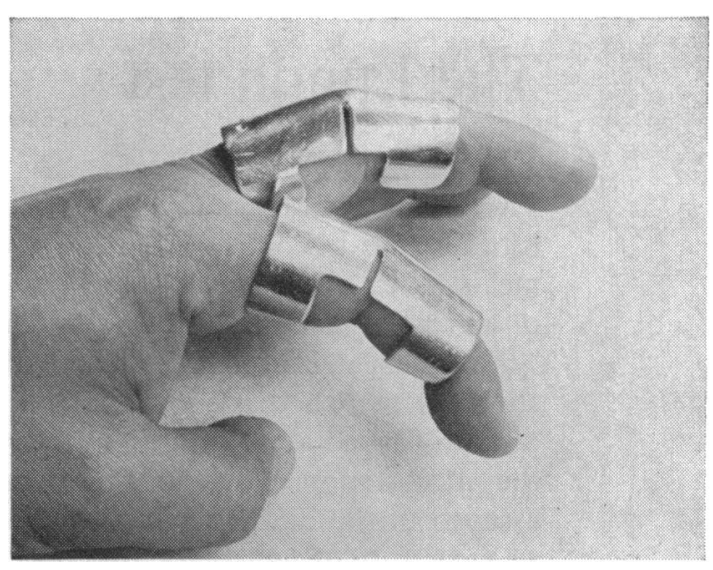

Fig Protective shields.

The completed apparatus appears in the figure. The fingers are fitted in the position the physician routinely uses at the time of endoscopy and the aluminium is thin enough to avoid hindering placing the instrument.

\section{Results}

Ordinary elective endoscopic procedures do not require the use of any finger guards but after using the device described here in 30 emergency procedures, intubation has proceeded satisfactorily and the examiner's hand remains intact.

Received for publication 17 April 1973. 